\title{
Management of Short Alveolar Bone with Implant Retained Splinted Crown
}

\author{
Primanda Nur Rahmania, Bambang Agustono, Nike Hendrijantini and Muhammad Dimas Aditya Ari \\ Department of Prosthodontic, Faculty of Dental Medicine, Universitas Airlangga, Surabaya, Indonesia
}

\begin{abstract}
Implant placement on maxillary posterior region has some limitations because of limited bone height, low bone density, and anatomical consideration involving the floor of the maxillary sinus. A 56-year-old male with a history of hypertension and stroke, consulted for edentulous in teeth 25 and 26 with limited bone height. A short implant for $26(\varnothing 4.8 \mathrm{~mm} ; 4 \mathrm{~mm})$ and $25(\varnothing 4.1 \mathrm{~mm} ; 10 \mathrm{~mm})$ were placed and splint crown was performed after 6 months.
\end{abstract}

Key Words: implant, alveolar bone, maxillary

\section{INTRODUCTION}

Patients with loss of teeth nowadays tend to choose implant to replace the missing teeth, because it can restore the stomatognathic function similar with the natural teeth. The advantages of using implant as a prosthetics include: no preparation on abutment teeth, and implant can be a permanent replacement, including tooth root. Furthermore, gingival margin can be shaped by the implant so the crown looks like natural teeth. Masticatory function with the implant is better than other prosthetic teeth. ${ }^{1}$

Placing an implant on the maxilla have some challenges, namely bone volume and maxillary sinus floor. The maxilla has a different type of bone compared with the mandible. Maxillary bone has a thin cortical layer around a low density trabecula. Maxillary sinus pneumatization occurs for the teeth that have been extracted long-time ago. It is thus quite challenging to place implants in the maxilla. ${ }^{2}$

Osseointegration is the key of success for implant placement. Without osseointegration, the implant cannot be retained in the bone. Implant perforation through the maxillary sinus membrane can cause sinus infection and implant failure. Studies report incidence of maxillary sinus membrane perforation at $7 \%$ to $35 \%$. Some ways to overcome this problem of implant in the maxilla include sinus lifting, bone graft, and in some cases, use of shorter implant ( $<10 \mathrm{~mm}$ length). ${ }^{3}$

Paper presented at the Joint Scientific Meeting in Special Care Dentistry, July 5, 2019, Amerta Room, 4th Floor, main campus of Universitas Airlangga, Surabaya, Indonesia.

Corresponding author: Primanda Nur Rahmania Department of Prosthodontic

Faculty of Dental Medicine

Universitas Airlangga

J. Mayjen. Prof. Dr. Moestopo No. 47 Surabaya 60132 - Indonesia

Email: primanda.rahmania@gmail.com

\section{CASE REPORT}

A 57-year-old male patient came to the Prosthodontics Clinic at Dental Hospital Universitas Airlangga, with major complaint of loss of teeth at some regions of the maxilla and mandibula. The patient wanted his masticatory function back. Patient had never used denture before. He had controlled hypertension, and had a stroke attack once. 
He had still been consuming drugs from his cardiologist who recommended implant placement surgery. Clinical intra oral examination found edentulous on teeth 16, 25, 26 and 36 , multiple diastema with a dental calculus in an anterior region. A clinical intraoral view can be seen in Figure 1.

Before the treatment was performed, the patient signed an informed consent. Then the preliminary impression was taken for study models using stock tray and an irreversible hydrocolloid (alginate); cast was done using type III gypsum. A CBCT analysis was then performed and found that the mesio-distal alveolar width in the 25 and 26 edentulous area was $16.69 \mathrm{~mm}$. In the 25 edentulous region, the alveolar crest to maxillary sinus floor width was $10.78 \mathrm{~mm}$, the bucco-palatal alveolar width was $9.31 \mathrm{~mm}$ and the alveolar thickness was 9.48 . In the 26 edentulous region, the alveolar crest to maxillary sinus floor width was $5.41 \mathrm{~mm}$, the bucco-palatal alveolar width was $10.51 \mathrm{~mm}$ and the alveolar thickness was 11.32 . The CBCT result is
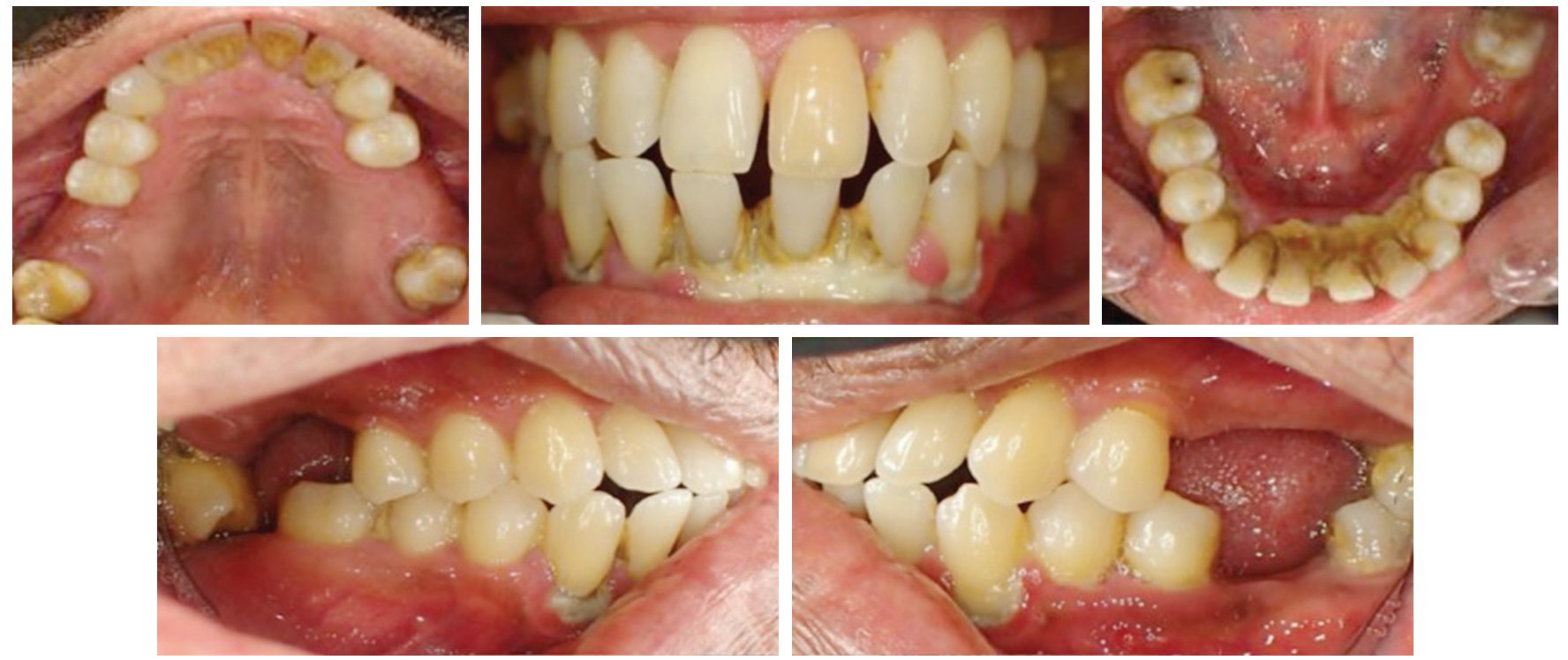

Figure 1. The intraoral clinical view.
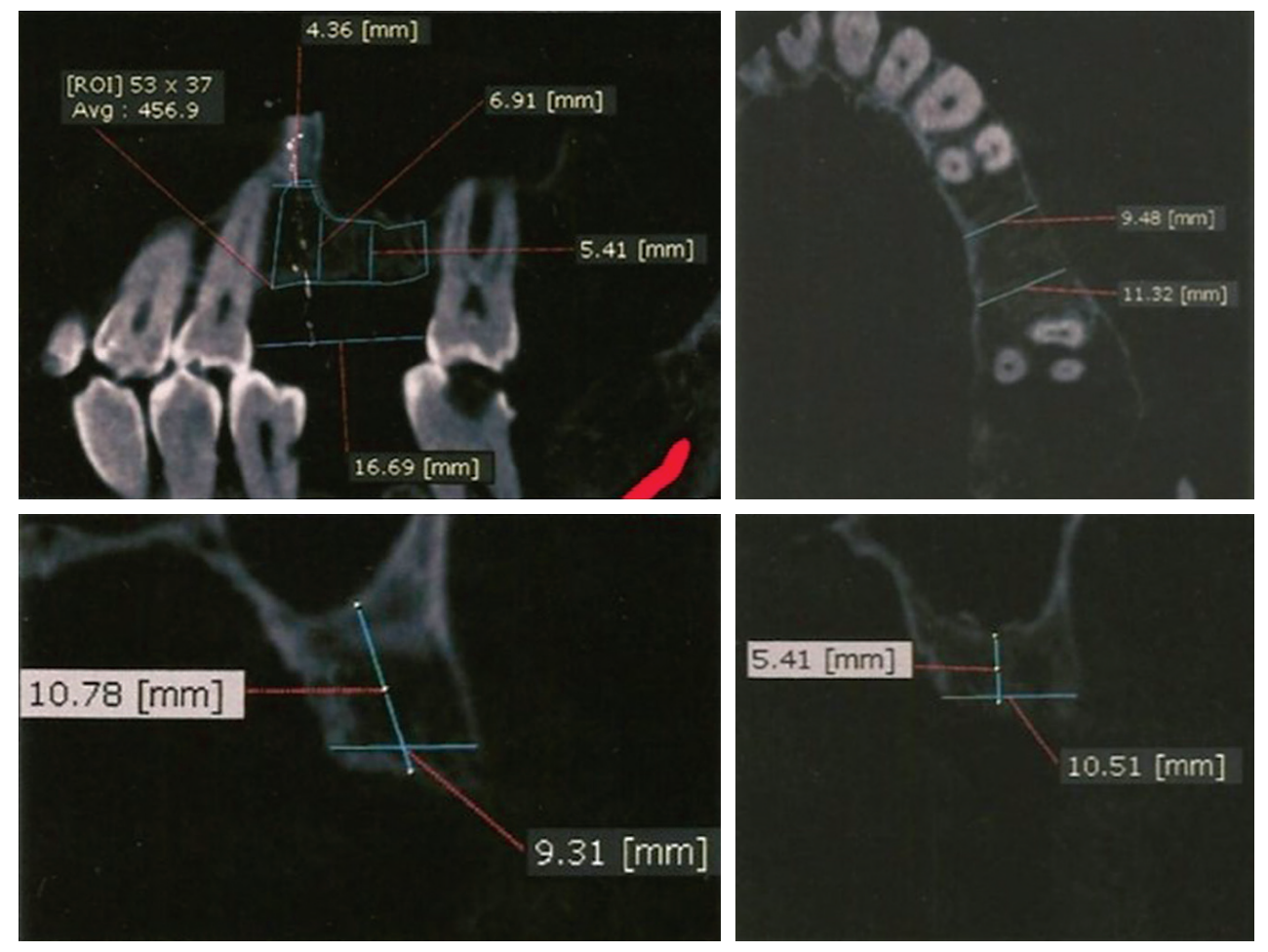

Figure 2. Sagittal, axial and coronal section of CBCT in region 25 and 26. 
shown in Figure 2. After the bone anatomical mapping was analyzed, the implant selection was determined. For region 25, the Straumann Standard Plus Implant SLA regular neck $\varnothing 4.1 \mathrm{~mm}$ RN (Tissue level implant), length $10 \mathrm{~mm}$ was selected while for region 26 , the Straumann Standard plus Implant SLA-active wide neck $\varnothing 4.8 \mathrm{~mm}$ $\mathrm{RN}$ (Tissue level implant), length $4 \mathrm{~mm}$, was selected.

Before surgery, scaling and root planning were performed and the conventional surgical template was made as guide for implant placement using an acrylic resin. The surgery began with local anesthesia using Articain 4\% + Epinephrine $\left(\right.$ Septocain $\left.{ }^{\circledR}\right)$. The incision on the alveolar ridge of the gingiva was performed followed by a full periosteal flap. This was followed by ridge flattening with round bur $\varnothing 2.3 \mathrm{~mm}$ at maximum speed $800 \mathrm{rpm}$. The template was then placed and initial drill was performed. Drilling was performed in region 25 by standard procedures then the implant was inserted with ratchet. In region 26 , the alveolar bone was drilled by standard procedure and the implant was inserted with ratchet. The healing cap was then placed and the flap was sutured (Figure 3). Periapical radiography was done for

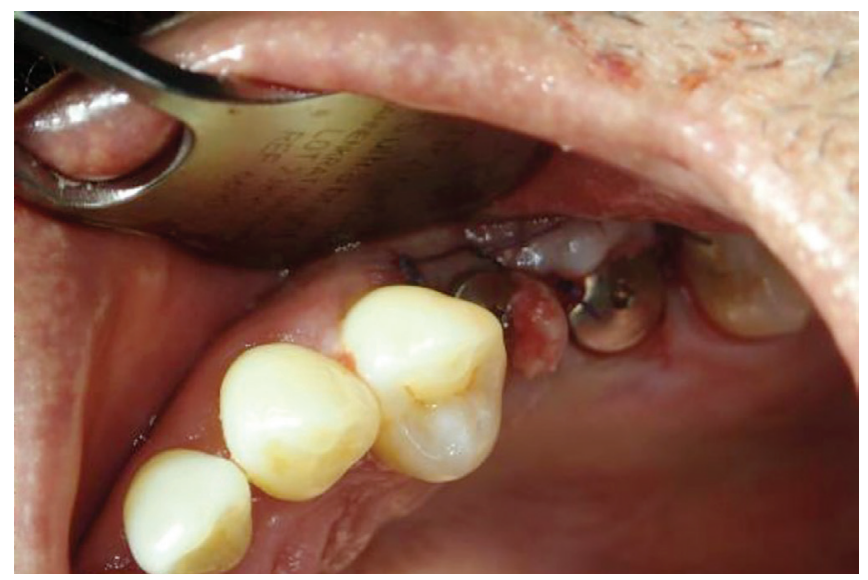

Figure 3. Clinical view after implant placement in region 25 and 26.

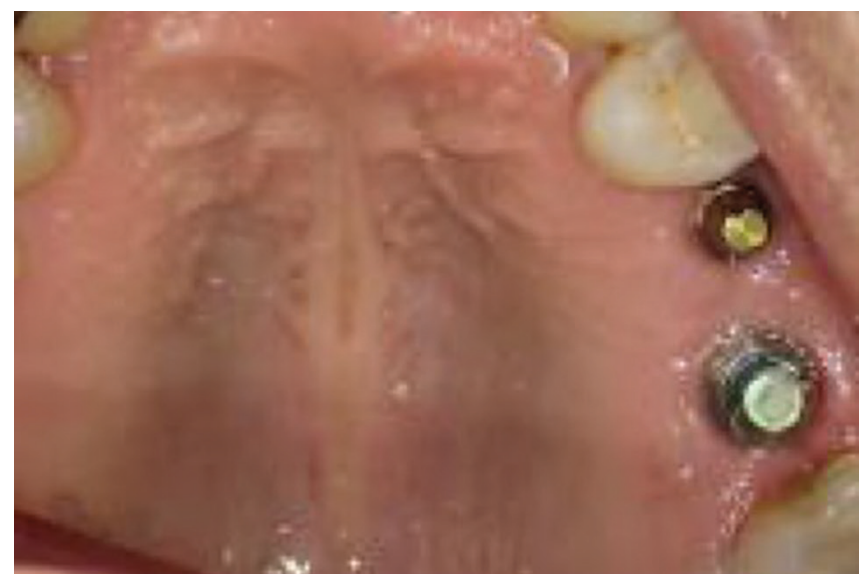

Figure 5. Abutment insertion in 25 and 26 implant. evaluation after implant placement and this can be shown in Figure 4 . The evaluation was done on the $1^{\text {st }}$ day, $1^{\text {st }}$ week, $1^{\text {st }}$ month, and 4 months after implant placement. The abutments were placed 4 months after the implant placement and the final impression was taken for the splint crown (Figure 5). After the final impression was taken, the temporary cap was inserted to both abutments, the impression was cast and the final model was prepared for the splint crown.

The splint crown was inserted using temporary cement and evaluated for 1 week. After 1 week, the splint crown was permanently inserted using Luting Glass Ionomer Cement (Figure 6). To improve masticatory function, the missing teeth in the lower jaw were also treated. The treatment was carried out in the form of fixed-fixed bridge with monolithic Zirconia material.

\section{DISCUSSION}

Case selection in implant treatment is the key to success. Placing implant on the maxilla have some challenges, namely bone volume and maxillary sinus floor. The maxilla

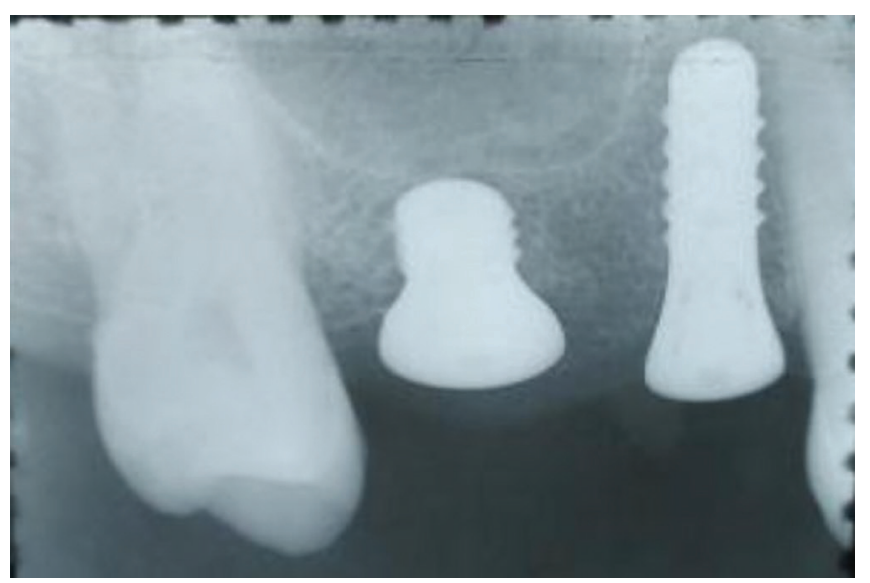

Figure 4. Radiographic evaluation of post implant placement in region 25 and 26.

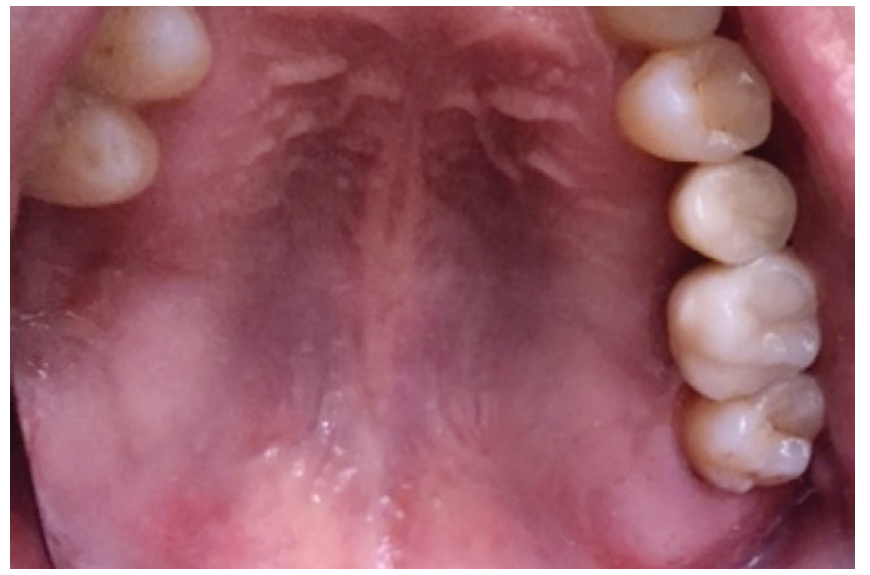

Figure 6. Splint crown insertion. 
has a different type of bone compared with the mandible. Maxillary bone has a thin cortical layer around a low density trabecula. ${ }^{2}$ It is impossible to use conventional implants in short alveolar ridge because of bone height condition. ${ }^{4}$

Some ways to overcome low bone height are sinus lifting and in some cases use of shorter implant $(<10 \mathrm{~mm}$ length). Studies about short implant in the maxilla reported that this kind of implant have the same success rate as the long implant ( $>10 \mathrm{~mm}$ length), with the right case selection. ${ }^{3}$ A clinical study with the $4 \mathrm{~mm}$ implant showed 94\% 5-year survival rate with minimal marginal bone loss and healthy peri-implant condition.

The maxilla has type IV bone quality. This type of bone has a thin cortical layer around a low-density trabecula. Compensations for this type of bone include choosing implant with texture and design that facilitate osseointegration. $^{2}$ Straumann Standard Plus Implant, which was used in this case, has a rough surface and textured thread. Rough Standard Plus implant increases surface contact area, so it could reach maximum mechanical stability between bone and implant. Textured thread could retain the blood clot and stimulate the healing process., ${ }^{2,5}$

In this case, SLActive Straumann implant was used. Advantage of SLActive implant are added roughness and hydroxylated titanium coating which has a hydrophilic property on implant surface that can induce osseointegration through a chemical pathway. ${ }^{6}$ SLActive is an implant surface process with coarse grit-blasting with $0.25-0.5$ corundum grit at 5 bar followed by acid-etching. SLActive has nitrogen protection to avoid air exposure, then stored in an air-tight glass tube containing $\mathrm{NaCl}$ solution. These added properties could maintain high surface energy by reducing adsorption of potential contaminant from the atmosphere. This is reciprocal with Smeets' study that high surface energy is the main characteristic that increases bone response to implant surface. ${ }^{7}$ According to Wennerberg's study, the SLActive can increase angiogenesis by osteoblast induction, thus accelerating the healing process and osseointegration. ${ }^{8}$

In this case, tissue level implant $4.1 \mathrm{~mm}$ diameter, $10 \mathrm{~mm}$ length was used on region 25 . On region 26 , tissue level implant used was $4.8 \mathrm{~mm}$ diameter, $4 \mathrm{~mm}$ length. Implant selection was based on bone width shown by CBCT radiograph. This is in agreement with Misch's study that implant diameter should leave $1 \mathrm{~mm}$ bone around implant. On region 26, implant with $4.8 \mathrm{~mm}$ diameter was used to increase the surface area so it could support the occlusal load on posterior region. ${ }^{9}$

Implant less than $10 \mathrm{~mm}$ length is categorized as short implant. Indication for $4 \mathrm{~mm}$ short implant is restoration on resorbed bone. Using short implant should be accompanied by using splint crown with another unit used to support long implant. ${ }^{5}$ The 3-year survival rate for Straumann short implant is $95.8 \%$ and 5 year survival rate is $93.4 \%$. Straumann short implant has the same survival rate as the conventional implant. It supported with the usage of splint crown protocol based on biomechanical theory for posterior location, so restoration on region 25 and 26 are splinted. ${ }^{4,10}$

Oral hygiene and good occlusal contact is the key for the long term survival of the implant, because a bad oral hygiene and bad occlusal contact can lead to bone resorption and can interfere with the osseointegration process. ${ }^{11}$ Patient evaluation every 3 months during the first year after implant placement should be done. Evaluation include: oral hygiene evaluation, occlusal harmony, implant and crown stability, peri-implant evaluation, and radiographic imaging.

\section{CONCLUSION}

Narrow alveolar height between alveolar crest and sinus floor can be managed with wide-neck and short-length implant and splint crown.

\section{Statement of Authorship}

All authors participated in data collection and analysis, and approved the final version submitted.

\section{Author Disclosure}

All authors declared no conflict of interest.

\section{Funding Source}

None.

\section{REFERENCES}

1. Nallaswamy D. Textbook of Prosthodontics, 1st ed. New Delhi: Jaypee Brothers Medical Publisher; 2004.

2. Bain CA, Weng D, Meltzer A, Kohles SS, Stach RM. A metaanalysis evaluating the risk for implant failure in patients who smoke. Compend Contin Educ Dent. 2002; 23(8):695-9.

3. Morand $M$, Irinakis $T$. The challenge of implant therapy in the posterior maxilla: Providing a rationale for the use of short implants. J Oral Implantol. 2007; 33(5):257-66.

4. Esfahrood ZR, Ahmadi L, Karami E, Asghari S. Short dental implants in the posterior maxilla: a review of the literature. J Korean Assoc Oral Maxillofac Surg. 2017; 43(2):70-6.

5. Straumann Dental Implant. Basic Information on the Surgical Procedures Straumann ${ }^{\circledR}$ Dental Implant System, 1st ed. Basel, Switzerland: Institute STraumann AG; 2007.

6. Zinelis S, Silikas N, Thomas A, Syres K, Eliades G. Surface characterization of SLActive dental implants. Eur J Esthet Dent. 2012; 7(1):72-92.

7. Smeets R, Stadlinger B, Schwarz F, Beck-Broichsitter B, Jung $\mathrm{O}$, Precht C, et al. Impact of Dental Implant Surface Modifications on Osseointegration. Biomed Res Int. 2016; 2016:6285620. doi:10.1155/2016/6285620.

8. Wennerberg A, Galli S, Albrektsson T. Current knowledge about the hydrophilic and nanostructured SLActive surface. Clin Cosmet Investig Dent. 2011; 3(1):59-67.

9. Misch CE. Contemporary Implant Dentistry. Mosby Elsevier; 2008.

10. French D, Nadji N, Larjava H. Survival and Success Rates of Short Straumann Implants Placed in the Mandible: A Retrospective Study with up to 5 Year Follow-Up. Glob J Oral Sci. 2015; 1(1):1-8.

11. Raikar S, Talukdar P, Kumari S, Panda SK, Oommen VM, Prasad A. Factors Affecting the Survival Rate of Dental Implants: A Retrospective Study. J Int Soc Prev Community Dent. 2017; $7(6): 351-355$. 